\title{
Field survey report and satellite image interpretation of the 2013 Super Typhoon Haiyan in the Philippines
}

\author{
E. Mas, J. Bricker, S. Kure, B. Adriano, C. Yi, A. Suppasri, and S. Koshimura \\ International Research Institute of Disaster Science (IRIDeS), Tohoku University, Miyagi, Sendai, 980-0845, Japan \\ Correspondence to: E. Mas (mas@irides.tohoku.ac.jp)
}

Received: 16 April 2014 - Published in Nat. Hazards Earth Syst. Sci. Discuss.: 27 May 2014

Revised: 14 March 2015 - Accepted: 17 March 2015 - Published: 10 April 2015

\begin{abstract}
Three weeks after the deadly Bohol earthquake of $M_{\mathrm{W}} 7.2$, which claimed at least 222 victims, another disaster struck the Philippines. This time, Super Typhoon Haiyan, also known as Typhoon Yolanda in the Philippines, devastated the Eastern Visayas islands on 8 November 2013. Its classification as a super typhoon was based on its maximum sustained $1 \mathrm{~min}$ surface wind speed of $315 \mathrm{kmh}^{-1}$, which is equivalent to a strong Category 5 hurricane on the SaffirSimpson scale. This was one of the deadliest typhoon events in the Philippines' history, after the 1897 and 1912 tropical cyclones. At least 6268 individuals have been reported dead and 1061 people are missing. In addition, a wide area of destruction was observed in the Eastern Visayas, on Samar and Leyte islands. The International Research Institute of Disaster Science (IRIDeS) at Tohoku University in Sendai, Japan, has deployed several teams for damage recognition, relief support and collaboration with regard to this disaster event. One of the teams, the hazard and damage evaluation team, visited the affected areas in the Eastern Visayas in mid-January 2014. In this paper, we summarize the rapid damage assessment from satellite imagery conducted days after the event and report on the inundation measurements and the damage surveyed in the field. Damage interpretation results by satellite images were qualitatively confirmed for the Tacloban city area on Leyte Island, the most populated city in the Eastern Visayas. During the survey, significant damage was observed from wind and storm surges on poorly designed housing on the east coast of Leyte Island. Damage, mainly from surface waves and winds, was observed on the east coast of Samar Island.
\end{abstract}

\section{Introduction}

Typhoons are tropical cyclone systems with high-intensity wind speeds. According to the intensity scale used by the Japan Meteorological Agency (JMA), a tropical cyclone is designated as a typhoon when the sustained wind speed exceeds $118 \mathrm{~km} \mathrm{~h}^{-1}$, and a super typhoon has winds of at least $190 \mathrm{kmh}^{-1}$. Super Typhoon Haiyan traveled at 30$40 \mathrm{~km} \mathrm{~h}^{-1}$ with a maximum 1 min sustained wind speed of $315 \mathrm{~km} \mathrm{~h}^{-1}$ (Daniell et al., 2013), reaching Category 5 on the Saffir-Simpson scale. Typhoon Haiyan hit the small nation of Palau causing some damage, but its maximum intensity was felt by the Eastern Visayas of the Philippines. Eight out of 17 regions were affected by the winds. The most impacted areas were Samar and Leyte islands, including the highly populated capital city of Tacloban. The last report, on 17 April 2014, included 6300 fatalities, 28689 people injured and 1061 who are still missing. A total of 3424593 families were affected in 44 provinces, with 1140332 houses either entirely or partially collapsed (NDRRMC, 2014). In addition, the Tacloban port and airport were affected by Super Typhoon Haiyan. On 11 November 2013, the president of the Philippines declared a state of national calamity. As a reference, Haiyan was the strongest cyclone since the year 2000 , with 1 min sustained wind speed over $300 \mathrm{~km} \mathrm{~h}^{-1}$. Among Category 5 cyclones since 2000, only Cyclone Sidr in Bangladesh caused more casualties than Super Typhoon Haiyan (Table 1).

Cyclone Nargis is not considered in this table because it was of Category 4; however the death toll was reported as being over 138000 fatalities (Fritz et al., 2009). From the list of cyclones in Table 1 it is worth highlighting that, although Super Typhoon Haiyan remains the strongest cyclone based on the peak 1 min sustained wind record since 2000 , in other 
Table 1. List of tropical cyclones of Category 5 Saffir-Simpson scale with fatalities recorded in the 20th century. P1SW: peak 1 min sustained wind in $\mathrm{km} \mathrm{h}^{-1}$; NAO: North Atlantic Ocean; EPO: eastern Pacific Ocean; WNPO: west North Pacific Ocean; NIO: north Indian Ocean; SWIO: southwest Indian Ocean; AR: Australian region; SPO: South Pacific Ocean.

\begin{tabular}{lrrrc}
\hline Name & Year & P1SW & Fatalities & Area \\
\hline Hary & 2002 & 260 & 4 & SWIO \\
Kenna & 2002 & 270 & 4 & EPO \\
Inigo & 2003 & 260 & 58 & AR \\
Heta & 2003 & 260 & 2 & SPO \\
Isabel & 2003 & 270 & 16 & NAO \\
Gafilo & 2004 & 260 & 237 & SWIO \\
Ivan & 2004 & 270 & 91 & NAO \\
Katrina & 2005 & 280 & 1833 & NAO \\
Rita & 2005 & 285 & 125 & NAO \\
Wilma & 2005 & 295 & 63 & NAO \\
Dean & 2007 & 280 & 40 & NAO \\
Gonu & 2007 & 270 & 78 & NIO \\
Sidr & 2007 & 260 & 15000 & NIO \\
Rick & 2009 & 285 & 3 & EPO \\
Ului & 2010 & 260 & 1 & SPO \\
Megi & 2010 & 295 & 69 & WNPO \\
Sanba & 2012 & 285 & 6 & WNPO \\
Phailin & 2013 & 260 & 45 & NIO \\
Haiyan & 2013 & 315 & 6268 & WNPO \\
Marie & 2014 & 260 & 3 & EPO \\
Vongfong & 2014 & 285 & 9 & WNPO \\
\hline
\end{tabular}

cases the intensity scale of wind does not necessary correlate directly to the number of fatalities. For instance, the 1970 Bhola Cyclone with $205 \mathrm{~km} \mathrm{~h}^{-1}$ wind speed and classified as Category 3 reported fatalities up to 500000 people (Kerry, 2005). Conversely, Hurricane Camille in 1969 was of Category 5 yet killed far fewer people: 259 . Moreover, Hurricane Katrina started as a Category 1 hurricane at its first landfall in Florida, USA. After this, due to warm waters of the Gulf of Mexico it increased to Category 5 and then decreased again to Category 3 at its second landfall in Louisiana, USA (Fritz et al., 2007). Such restructuring of wind fields before landfall make it difficult to rely on storm surge or damage prediction based only on offshore estimates of wind speed; however some interesting efforts can be found in the literature, such as Jordan II and Clayson (2008).

A rapid assessment of the event using satellite images for damage interpretation was conducted immediately by the authors, and a post-event survey of Super Typhoon Haiyan's impact on the Philippines was carried out by the International Research Institute of Disaster Science (IRIDeS) team in midJanuary 2014. The results of these activities are presented in this paper.

\section{Overview of Typhoon Haiyan}

Super Typhoon Haiyan, known as Typhoon Yolanda in the Philippines, formed in an area of low pressure at low latitudes in the west Pacific Ocean near Pohnpei in the Caroline Islands group in the Federated States of Micronesia. It was 3 November 2013 when the system developed into a tropical depression and later into a tropical storm, with the name Haiyan given at 00:00 UTC on 4 November. By 5 November, the intensity of the tropical storm had increased rapidly to the typhoon category, and on 6 November the Joint Typhoon Warning Center (JTWC) classified it as Category 5 on the Saffir-Simpson hurricane wind scale; later that day, it entered the Philippine Area of Responsibility (PAR) (NDRRMC, 2014). On 8 November, Super Typhoon Haiyan made landfall in the Philippines at Guiuan, Eastern Samar, and continued its way west-northwest across the Eastern Visayas (Fig. 1). The second landfall occurred over Tolosa on Leyte Island at 07:00 LT. According to survivors interviewed at Tacloban, north of Tolosa, 07:00 LT is also the time when the surge began to inundate and washed away houses on the coast near the city. A third landfall happened over Daanbantayan in Cebu at approximately 09:40 LT. By the end of the day and into the next afternoon, the typhoon weakened towards the West Philippine Sea, and, finally, it was reported to be outside the PAR. Details of the event can be seen online in survivor videos, in particular those from cyclone hunters such as the iCyclone group (Morgerman et al., 2014). Here, we quote some of the observations by Morgerman et al. (2014) of the event experienced by his team in the Tacloban city downtown area: "Haiyan was a small, fastmoving, extremely violent cyclone that made a direct hit on Tacloban City". According to this chase report Haiyan presented destructive winds starting at 06:45, with the highest winds and heaviest rain occurring at approximately 07:25. Their estimations suggest a storm surge of 20 to $30 \mathrm{ft}$ ( 6 to $9 \mathrm{~m}$ ), observed as a sudden rise of the sea at 07:30, which reached its highest peak between approximately 08:00 and 08:15, with lightning and thunder occurring during this interval. A storm surge inundation and destructive winds were observed from 06:45 to 08:45, a short-duration event compared with other tropical cyclones. Nevertheless, Typhoon Haiyan was one of the strongest and deadliest typhoons in Philippine history. As of 17 April 2014, from the last official report, 6300 fatalities have been reported, with 28689 persons injured and 1061 still missing due to the typhoon's aftermath (NDRRMC, 2014; Tajima et al., 2014; Mas et al., 2014; Mori et al., 2014).

\section{Damage interpretation from satellite images}

After disasters with wide areas of impact, information related to the extent of damage and the areas in need of assistance and relief is often limited. Satellite imagery can provide dis- 


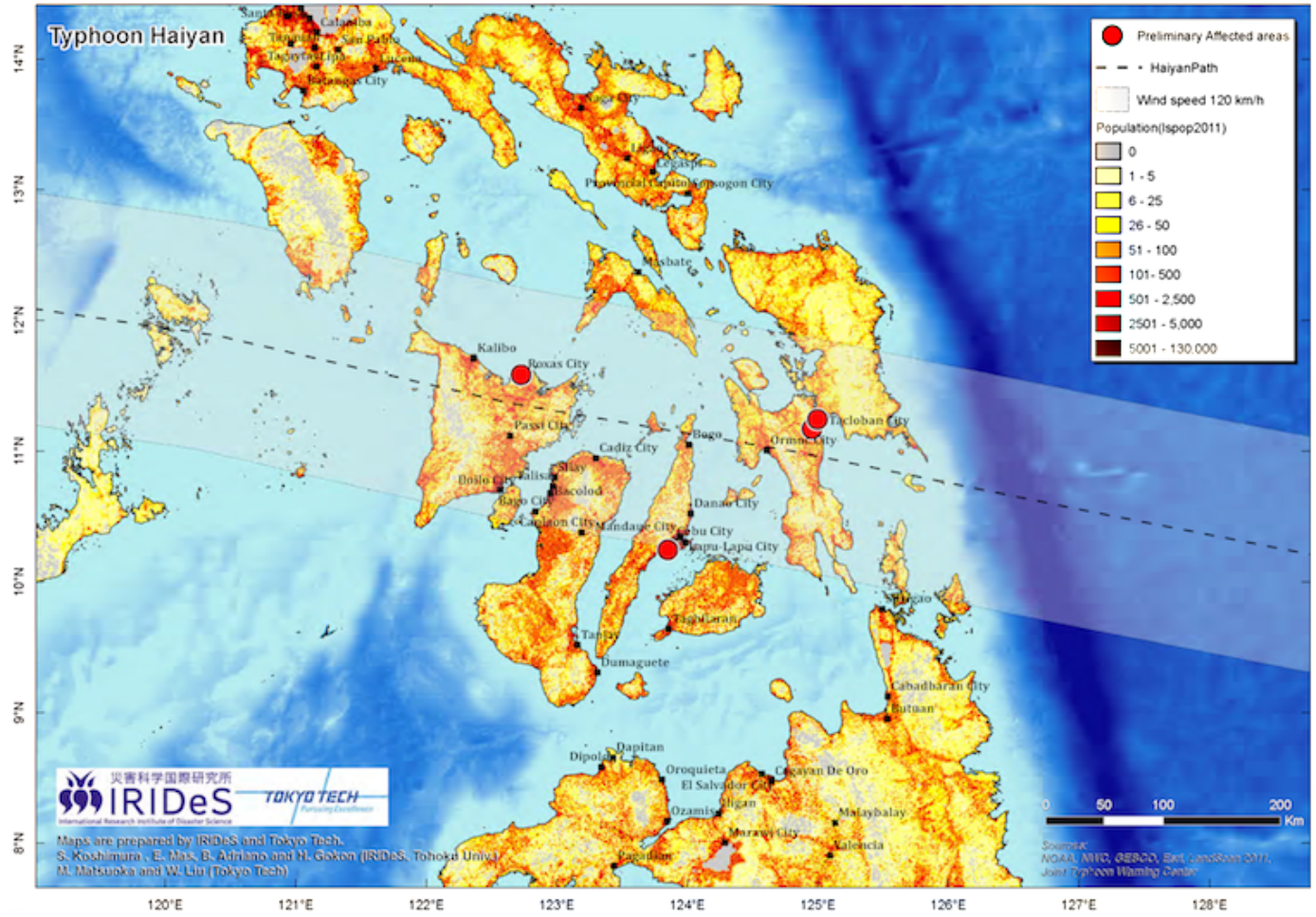

Figure 1. Track of Super Typhoon Haiyan through the Philippines Area of Responsibility (PAR) overlaid on the LandScan population data. Almost 4 million families were affected across 44 provinces of the Eastern Visayas.
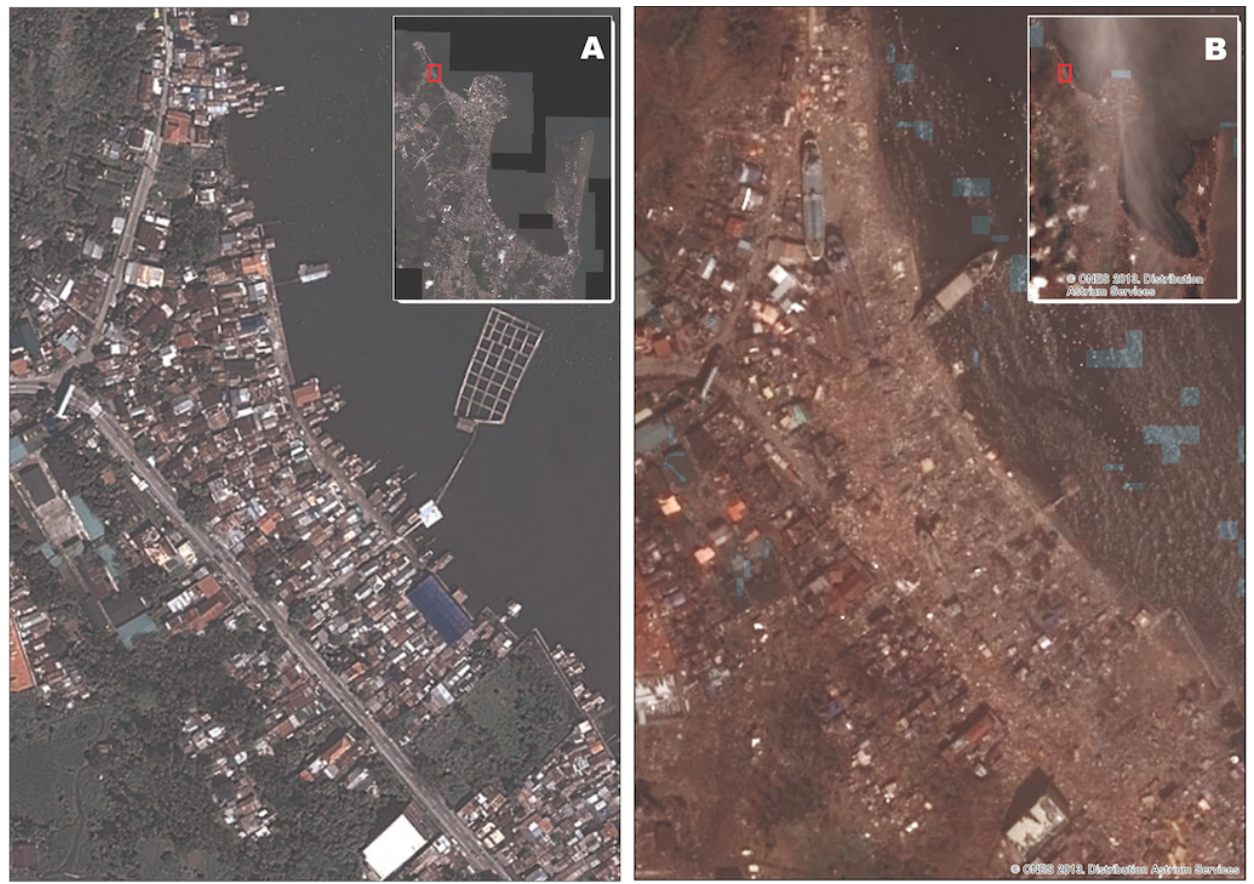

Figure 2. (a) Pre-event satellite image obtained from a mosaic of Google Earth snapshots (imagery date: 23 February 2012). (b) Post-event Pléiades/Astrium service satellite image. In addition, a Digital Globe image in Google Earth was used for areas in the northern part of the study area (imagery date: 13 November 2013). 
aster information, including the extent and level of damage in areas with limited accessibility, used to support emergency response (Wegscheider et al., 2013). Such efforts have been conducted after earthquakes, tsunamis and hurricanes (e.g., Hurricane Katrina and the Great Tohoku earthquake, tsunami and nuclear accident) (Barnes et al., 2007; Ramírez-Herrera and Navarrete-Pacheco, 2012; Gokon and Koshimura, 2012). This paper describes IRIDeS' initial efforts using satellite imagery to map the damage in the Tacloban area from Super Typhoon Haiyan. The damage assessment approach used for this event was the manual visual interpretation method. Visual interpretation is one of the most straightforward methods to assess damage in a wide area, and it is the most accurate (Koshimura et al., 2009; Suppasri et al., 2011; Mas et al., 2012; Wegscheider et al., 2013) when using very high resolution imagery. Some limitations to this method are its use of subjective interpretation, which can vary from user to user; that the availability of satellite images of the impacted area depends on weather conditions; and that it is time consuming. In addition, underestimations in the interpretation of damage conditions due to storm surge inundation might have occurred where the structure was not damaged on its roof due to a high resistance to winds. In this study, it was confirmed later during field survey that the main roofing type is corrugated galvanized iron (CGI) sheets, which posses low resistance to strong winds.

\subsection{Data description}

This study uses pre- and post-event satellite images to identify damage to building roofs. Pre-event satellite imagery of Tacloban city taken on 23 February 2012 was readily accessible through Google Earth, while post-event remote sensing data of the damaged area were obtained on 13 November 2013 through Digital Globe in Google Earth and through CNES Pléiades/Astrium imagery from the ArcGIS map service. The two images are shown in Fig. 2.

\subsection{Damage visual inspection and mapping}

A visual comparison of the pre- and post-event images was conducted with a house-by-house assessment of the damage due to Super Typhoon Haiyan. A house or structured was considered damaged if it had a partially or entirely damaged roof or, in extreme cases, if it had been washed or blown away. The damage assessment was classified into only two categories to accelerate interpretation, as rapid assessment of the event was necessary. The categories are as follows:

- High damage or destroyed. For this classification, the interpretation focused on the roofs that had been reduced by more than $50 \%$ between pre- and post-event images. In addition, when the structure had been washed or blown away, it was defined as destroyed.

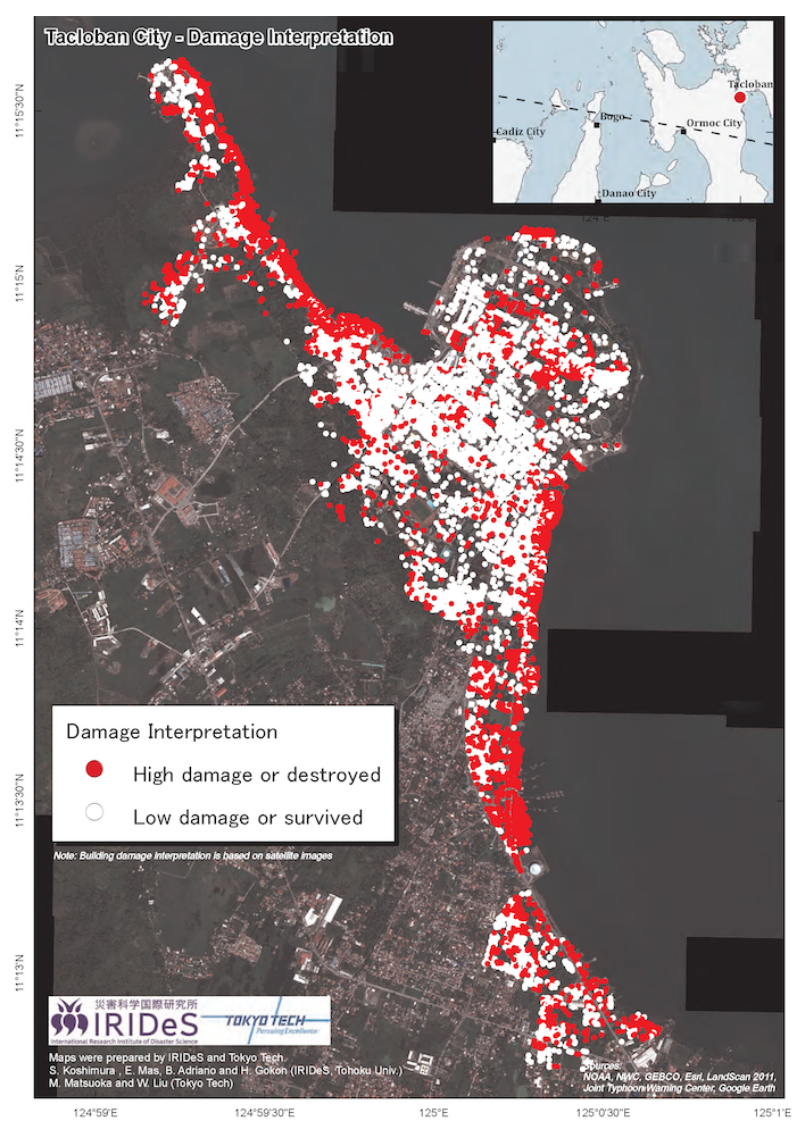

Figure 3. The results of the visual damage assessment using preand post-event satellite images and two classification criteria. (i) High damage or destroyed in red and (ii) low damage or survived in white.

- Low damage or survived. For this classification, the visual interpretation focused on the structures with only small variations in geometry or roof shape. In addition, when there was no visual variation, if the structure was near an expected flooded area, the level was classified as low damage or survived due to the uncertainty on damage by the storm surge and resistance of roof to the strong wind.

The results of this assessment are shown in Fig. 3. Significant damage was interpreted on the coasts to the north and south of downtown Tacloban. During our field survey, we visually confirmed the extensive damage in these areas. The verification of our interpretation is, at this moment, qualitative due to the difficulties experienced during the field survey in gathering detailed information at a house-by-house resolution (Fig. 4). The extensive damage interpreted to the north and south of the downtown was confirmed to be due to the high vulnerability of the structures in these areas and to the presence of stranded ships, which caused most of the damage near the Anibong area (Fig. 5). In addition, areas interpreted as having high damage in Fig. 3 are correlated to high 


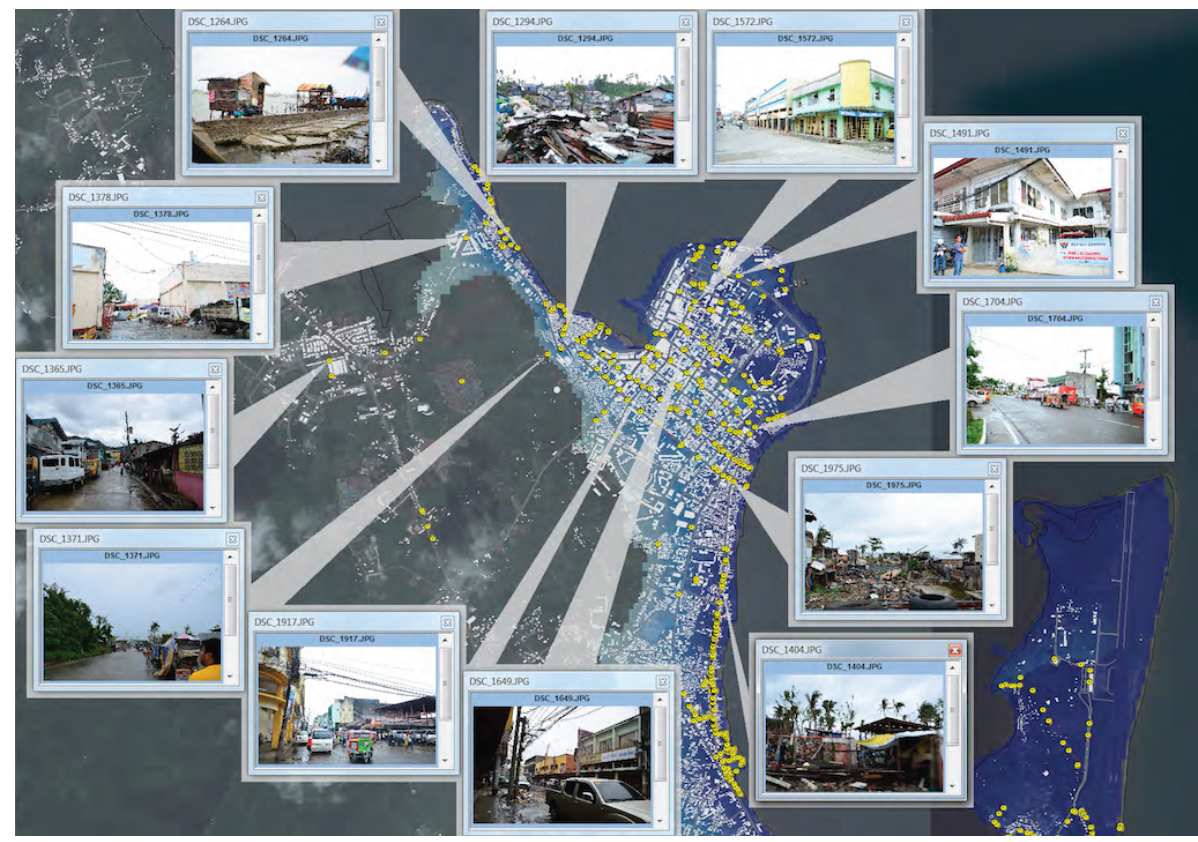

Figure 4. Photos taken during the field survey at the areas assessed through visual inspection of satellite images. The damage conditions and distribution confirm the interpretation that higher damages existed to the north and south of the downtown area in Tacloban city, the Philippines.
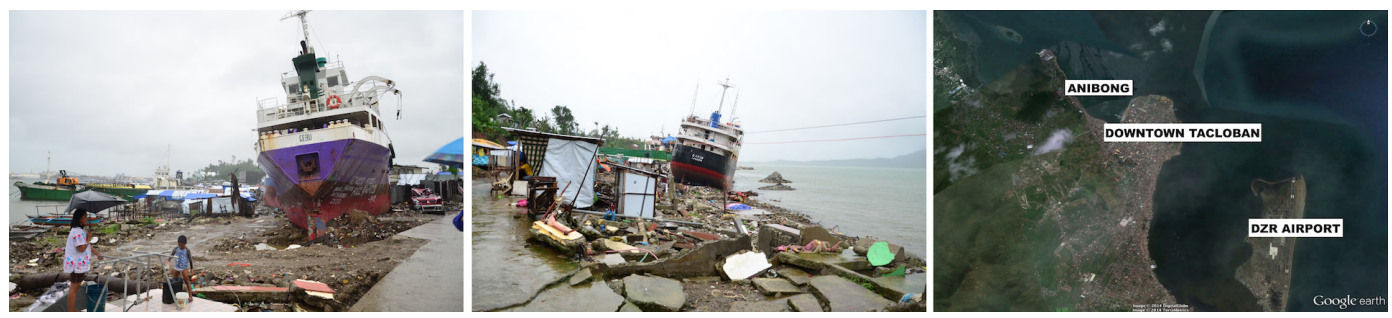

Figure 5. Stranded ships near the coast of Anibong to the north of the Tacloban downtown area. The storm surge was measured at approximately $6 \mathrm{~m}$, and extensive damage was confirmed.

storm surge inundations measured in the survey and shown in Fig. 7.

\section{Field survey of the areas affected by Super Typhoon Haiyan}

\subsection{Dispatch of IRIDeS survey team}

In mid-January, the IRIDeS of Tohoku University deployed a second group to coordinate field survey efforts in the affected areas in the Eastern Visayas. The field survey team inspected the affected areas to determine the extent of inundation and to comprehend the mechanisms of the structural and building damage through inspection and measurement of inundation heights. Observations and measurements of the storm surge inundation and the ongoing recovery of Tacloban and the surrounding affected areas are reported in this paper.
The team was dispatched on 14 January 2014, and they surveyed the areas shown in Fig. 6.

\subsection{Objectives of the survey}

1. Gather the available data to verify the rapid damage assessment conducted using satellite image analysis, as explained in the previous section.

2. Measure inundation heights from storm surges and surface waves to verify the numerical models - the outputs of the numerical simulation are presented in Bricker et al. (2014).

3. Establish a collaborative partnership to evaluate the impacts on the mental health of the people affected by the disaster (IRIDeS, 2014). 


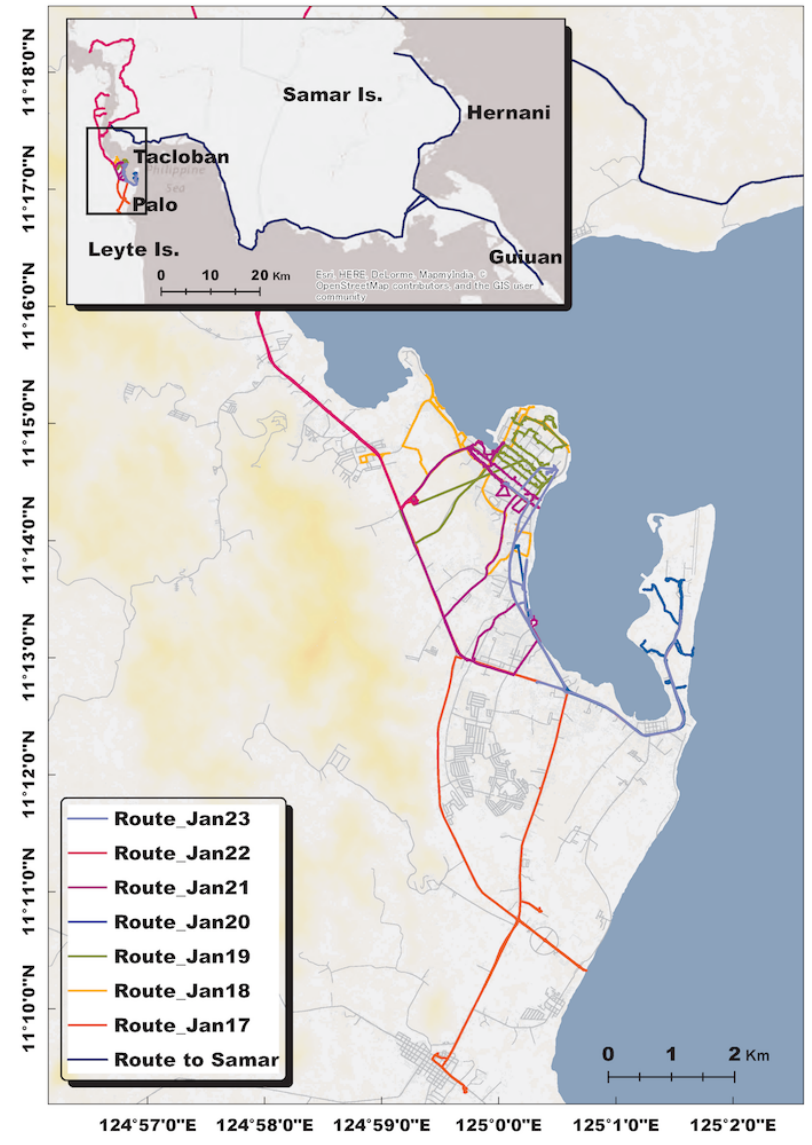

Figure 6. The colored lines show the daily survey routes of the team. Areas surveyed: Palo, Candahug (McArthur Park), Tacloban airport, Magallanes, downtown Tacloban (green route), Anibong, Northern Leyte, Western and Eastern Samar, Guiuan and Hernani.

\subsection{Overview of the survey}

The team was divided at Tacloban city into two groups, the hazard and damage evaluation group and the disaster medicine group. The first group focused on the first two objectives of the mission, while the second group was in charge of the third objective. Local counterparts joined both groups for support and for future collaboration. The locations of the storm surge and wave inundation measurements in the visited areas are shown in Fig. 7. These measurements were conducted using portable laser rangefinders calibrated to the sea level at the time of the survey. A supplement related to this article with the table of measurements is available online. Extensive damage to buildings from wind and surges was observed in the Tacloban city coastal area. In particular, houses made of rafters with CGI sheets on the roof were blown or washed away. Storm surge heights of up to $6 \mathrm{~m}$ were measured near the shoreline. Moreover, survivors reported waves over the surge, which could have been nearly $4 \mathrm{~m}$ high. Damage to housing was also observed from ships that were carried by storm surge and storm waves to in-

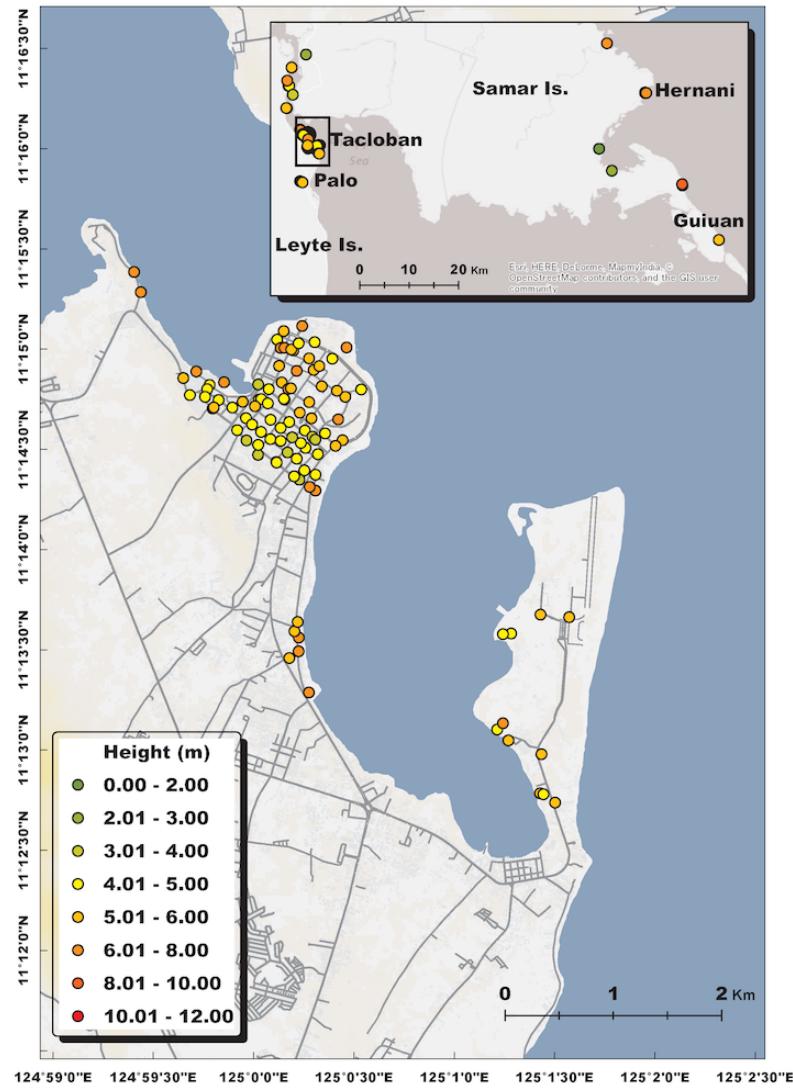

Figure 7. Storm surge inundation (Leyte Island and western Samar Island) and surface wave heights (eastern Samar Island) with respect to the local mean sea level.

land areas. In downtown Tacloban, buildings are made of masonry or reinforced concrete and suffered slight damage from wind and ground floor inundation; however, significant structural damage was not observed to most of the buildings. In contrast, areas to the northwest and southeast of downtown Tacloban were highly impacted due to the lightweight materials used for construction and the non-engineered characteristic of the houses. Conversely, Daniel Z. Romualdez (DZR) Airport at Tacloban was heavily damaged by strong winds and surges from 4 to $6 \mathrm{~m}$ in height. The airport was reopened for humanitarian aid 3 days after the disaster, and, by the time of our field survey, it had reopened for domestic flights. Survivors were interviewed during the field survey, and they reported having resisted the surge by clinging to palm trees or staying on rooftops. Most of the local residents did not evacuate rapidly because they overlooked storm warnings as their previous experiences had not been as critical as Typhoon Haiyan. In addition, to protect their assets and belongings, some of them stayed at home instead of looking for high ground or refuge. The warning information of Haiyan was issued by the Philippine Atmospheric, Geophysical and Astronomical Services Administration (PAGASA) officially through a weather advisory at 11:00 on 5 

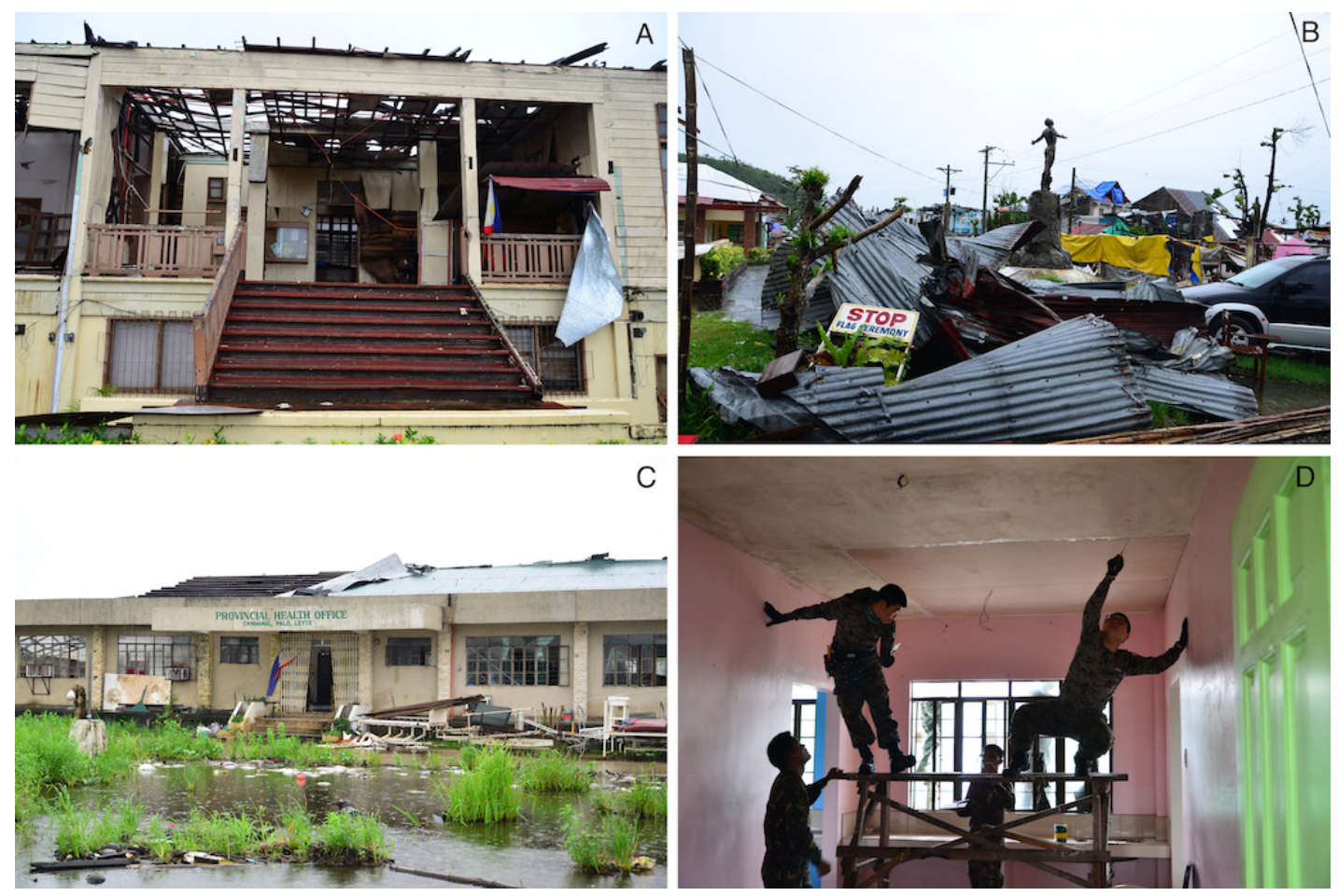

Figure 8. (a, b) Damage observed at the School of Health Science at the University of the Philippines, Manila. (c) Damage to the Provincial Health Office building in Palo. (d) The South Korean army helping with the restoration of a local hospital in Palo.

November and then upgraded to a severe-weather bulletin on 6 November. This information was transfer to the National Disaster Risk Reduction and Management Council (NDRRMC) and from here to national, regional and local offices in charge of convey population to evacuation. The estimations of PAGASA were accurate and distributed $18 \mathrm{~h}$ before the landfall in Guiuan. Still, fatalities were reported due to a delayed evacuation.

\subsection{Damage observed on Leyte Island}

Leyte Island is in the Visayas group of islands in the Philippines. It is located in the Eastern Visayas, and its capital city is Tacloban on the eastern shore in the northwest of Leyte Gulf. The city of Tacloban has suffered previous destruction and loss of life during the typhoon of 1897 and the 1912 tropical storms. This time, Super Typhoon Haiyan struck the city of more than 200000 inhabitants, causing massive destruction and death. The storm surge was measured to be between 4 and $6 \mathrm{~m}$ in the downtown area; $6 \mathrm{~m}$ to the south; and up to $8 \mathrm{~m}$ to the north of downtown Tacloban, in the Anibong area. Damage due to wind was present throughout the survey area. The major mechanism of wind damage was the ripping of the roofing materials off the frames of structures. The most common roofing material is CGI sheets, which are popular because of their low cost and ease of installation. They are attached to the roofing frame/rafters (usually wooden, though sometimes metal) by nails. A common mechanism of fail- ure is the nails ripping through the CGI sheet. Sometimes the sheets and the nails are different metals, which can accelerate corrosion of both the nail and the sheet, further weakening the attachment. Once a structure's roof had been destroyed, rain poured into the structure, ruining the architectural elements, equipment, furniture and other items inside.

\subsubsection{Municipality of Palo}

Palo is a neighbor to Tacloban city, in the south of Leyte, the Philippines. It was also heavily damaged, with several residents killed during the typhoon. The survey team visited the School of Health Science at the University of the Philippines, Manila, and found extensive damage to its infrastructure. In addition, hospitals in the area suffered from winds and the surge. Significant structural damage was not observed other than to roofs; however, equipment, medical supplies and windows were destroyed (Fig. 8).

\subsubsection{Daniel Z. Romualdez Airport in Tacloban}

DZR Airport is located on the edge of the eastern peninsula of the Tacloban city area. This is a domestic airport with flights from Manila and Cebu. It was effectively destroyed by winds and storm surge inundations of, at most, $6 \mathrm{~m}$ in height. Walls, the roof and equipment were damaged. It was reopened for emergency relief 3 days after the disaster and, later, for limited commercial flights. At the time of 

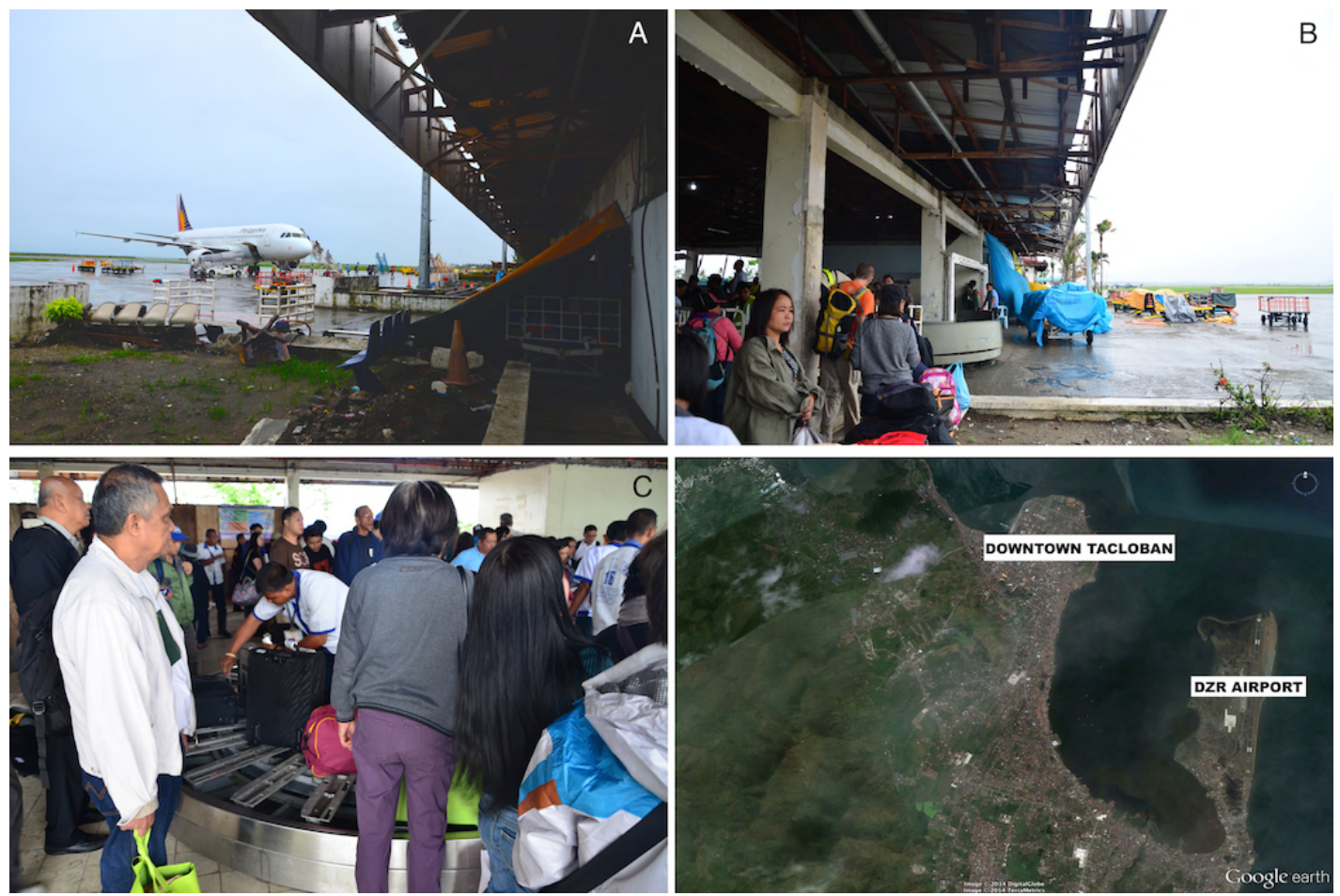

Figure 9. (a, b) Damage to the walls and roof of a gate to the side of the runway. (c) Passengers arriving and baggage claim belt out of service due to damage.

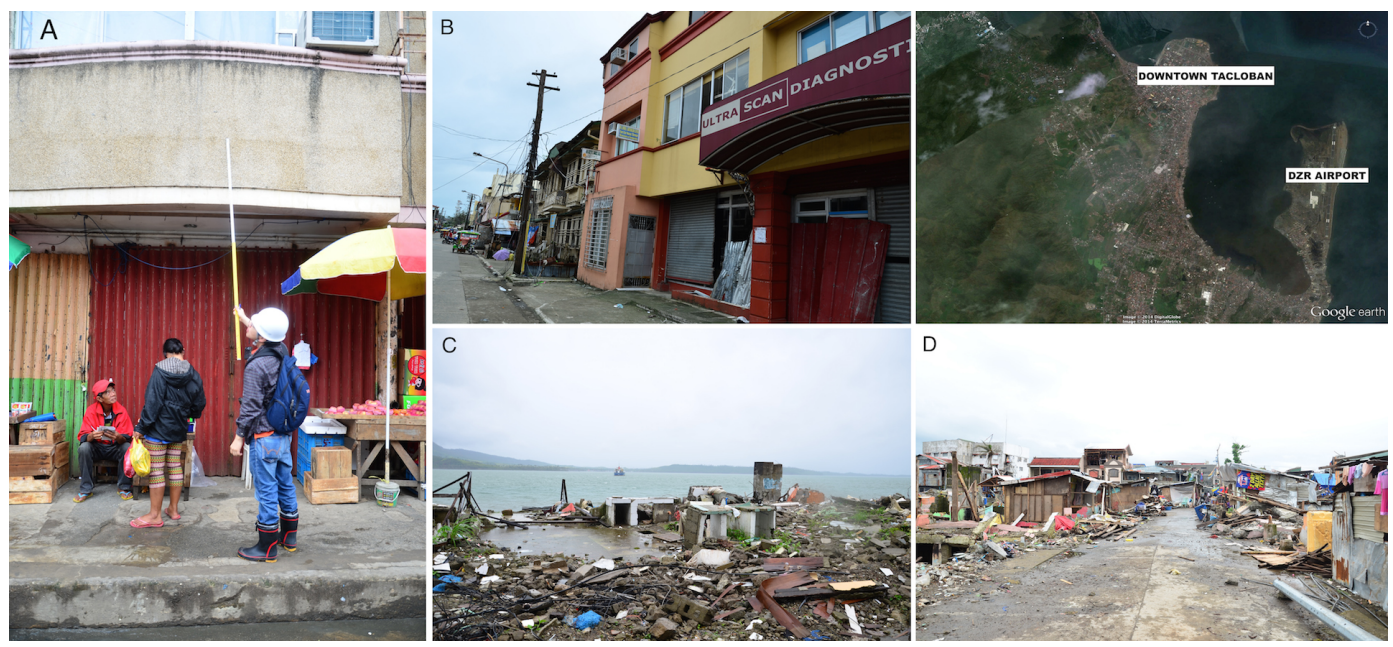

Figure 10. (a) Watermark in the inland downtown area, where no structural damage was observed. (b) Inland downtown, damage to doors due to flooding. (c, d) Extensive damage at the coastline near downtown Tacloban.

the field survey, no electricity, water, walls or baggage claim belts were available, as shown in Fig. 9.

\subsubsection{Downtown Tacloban}

Downtown Tacloban, as recognized by the survey team, comprises the area located at the head of the second peninsula to the west of DZR Airport. In downtown Tacloban, build- ings were dirtied by the storm surge and by rain falling in through roofs that had been blown away. Some soft walls and windows were broken, and equipment, furniture and architectural elements inside these buildings were ruined. However, structural damage (other than to roofs) was not severe (Fig. 10). Conversely, the coastal areas of Tacloban, some near downtown, were struck by wind, the storm surge and surface waves on top of the surge. The complete collapse 


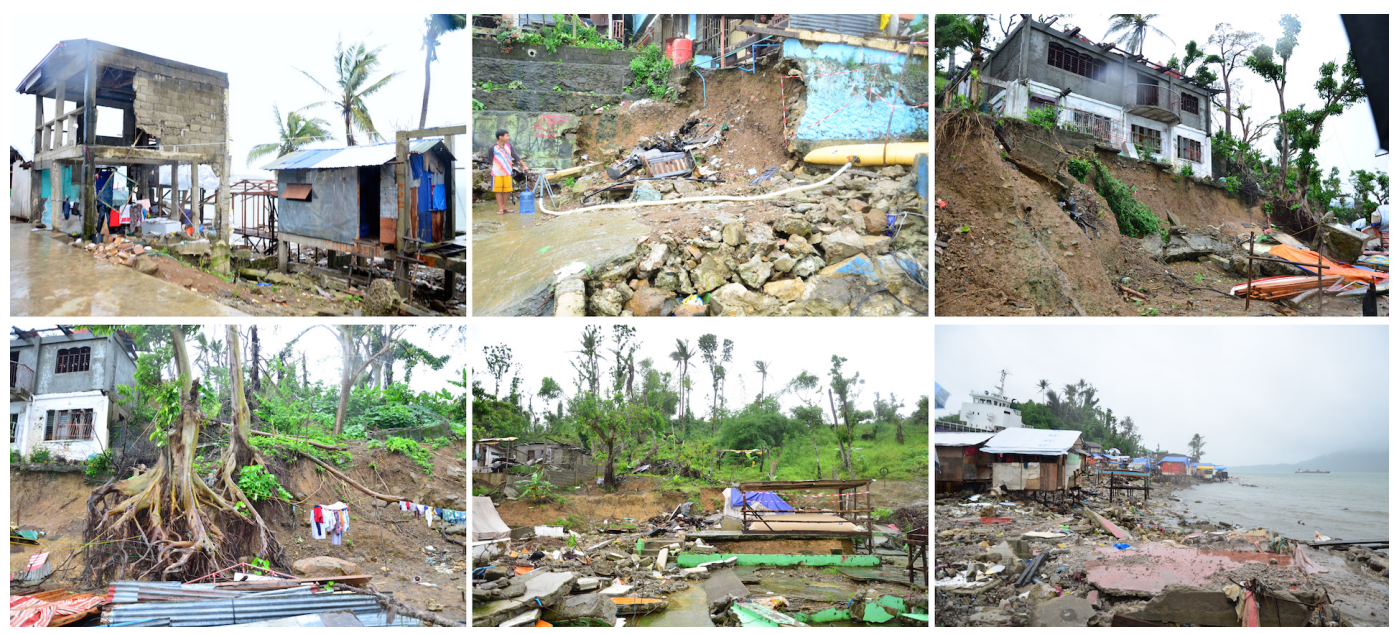

Figure 11. Damage observed at the Anibong area, north of downtown Tacloban. Destruction of wooden pile dwellings, erosion and local instability of slopes.
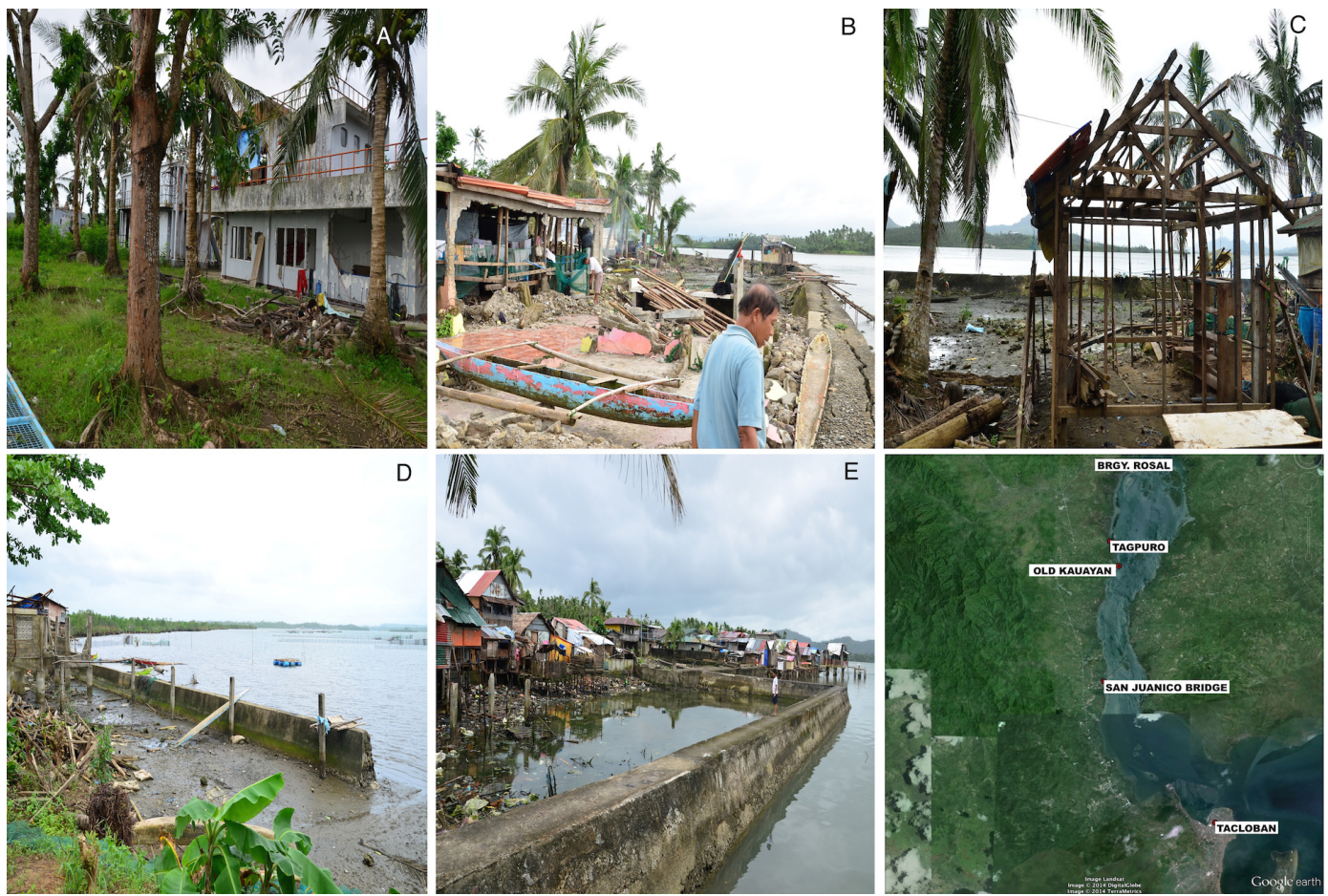

Figure 12. Damage at the northern part of Leyte Island. (a) Structure near the San Juanico Bridge. Inundation height was measured at $5.9 \mathrm{~m}$. (b, c) Coastal village of Old Kauayan, where a small sea wall was overtopped and damaged. Surge flooding of $4.4 \mathrm{~m}$ was measured here. (d) Sea wall damage at Tagpuro. The run-up height was $6.9 \mathrm{~m}$. (e) Barangay Rosal area with a $5.0 \mathrm{~m}$ storm surge inundation and damage to houses behind the $3.0 \mathrm{~m}$ sea wall.

of lightweight-material houses was observed. Residents have reconstructed temporary private refuges with debris from the disaster.

\subsubsection{Anibong area}

The Anibong area is located immediately to the north of downtown Tacloban, in the coastal area of Panalaron Bay. The Anibong and neighboring barangays (villages) were intensely damaged by the storm surge, the winds and the waves. Ships stranded here were the main cause of damage 

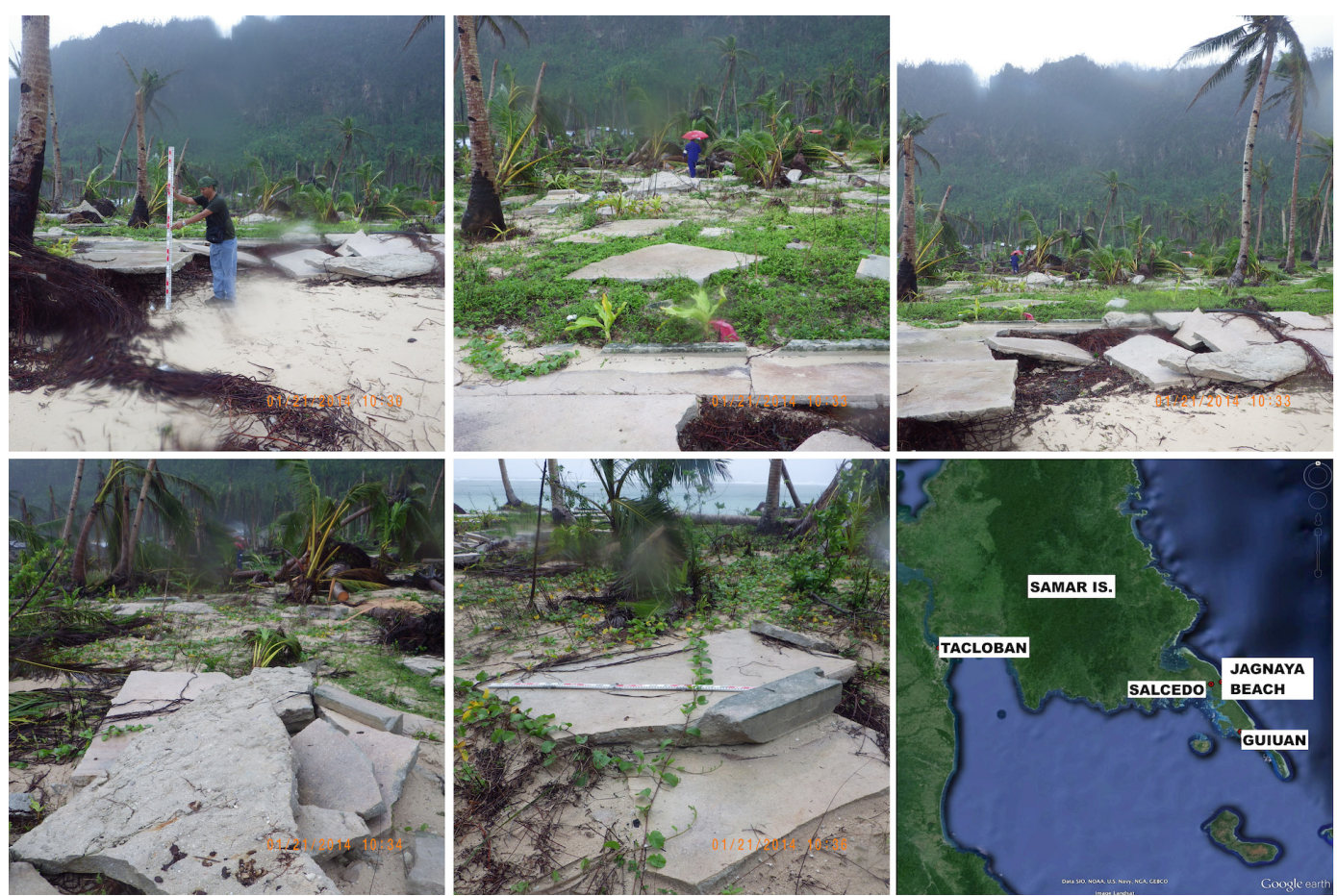

Figure 13. Guiuan village, one of the areas most affected by storm surge and superimposed storm waves. Sand erosion, vegetation damage and destroyed concrete structures were observed.

in the area (Fig. 5). Behind Anibong, a steep hill functioned as a barrier to the surge; however, the hill remains unstable due to the erosion of its slopes. Figure 11 shows the damage to concrete frame structures; a local landslide and soil erosion were deep enough to uncover house foundations and tree roots. Pile dwellings, or palafittes, are the main type of house found in this area. Due to these houses' lightweight building materials and their wooden piles not being deep enough in the sandy soil, this was one of the most vulnerable places in the Tacloban city area.

\subsubsection{Northern areas of Leyte Island}

Driving north from Tacloban city, Leyte Island is connected to Samar Island by the San Juanico Bridge. We surveyed the area and found flooding heights up to $5.9 \mathrm{~m}$ with damage to equipment and furniture inside concrete structures. No significant structural damage was reported in these areas. Farther to the north, along the San Juanico Strait, villages such as Old Kauayan and Tagpuro were affected by surge inundations between $4 \mathrm{~m}$ and $6 \mathrm{~m}$ high and by a measured run-up on the hill of Tagpuro of $6.9 \mathrm{~m}$ in height. In Old Kauayan, there was extensive damage to coastal wooden houses and to the community school. A seawall of $3 \mathrm{~m}$ was overtopped, and the flow generated scour at the wall's landward side. The northern part of the area visited by the team was Barangay Rosal, where the local mayor described the event and reported heights up to $5 \mathrm{~m}$. Significant damage was observed to pile dwellings located behind a $3 \mathrm{~m}$ high seawall, which was overtopped by the storm surge, and roofs were ripped off by the winds. The storm surge mainly affected the west side of the San Juanico Strait, from the bridge up to the north (Fig. 12).

\subsection{Damage observed in Samar Island}

Little damage from the storm surge was observed on the northern side of the San Juanico Strait on western Samar Island. The team visited three locations here, and only one small village next to the San Juanico Bridge presented houses affected by the surge. However, wind did rip off many lightweight roofs in the villages in the west of Samar Island. Most of these houses were already reconstructed using the same corrugated galvanized iron blown off by the wind. Most of the damage at Samar Island was observed on the east coast, facing the Pacific Ocean. Here, debris and witness accounts indicate inundation and run-up to $11 \mathrm{~m}$ a.s.l. (Fig. 13). Many coastal, concrete-based structures were entirely destroyed, with concrete blocks from walls and foundations deposited up to $30 \mathrm{~m}$ inland by the wave force. The coralfilled seawall in Hernani was breached at multiple locations, and substantial scour existed on the beach. Coral boulders were found on the beach at an elevation of $5 \mathrm{ma}$ a.s.l., possibly transported there by Haiyan's waves (Fig. 14). Most witnesses reported a typical wave attack, with water approaching and then retreating over a period of 10-20 s. However, 

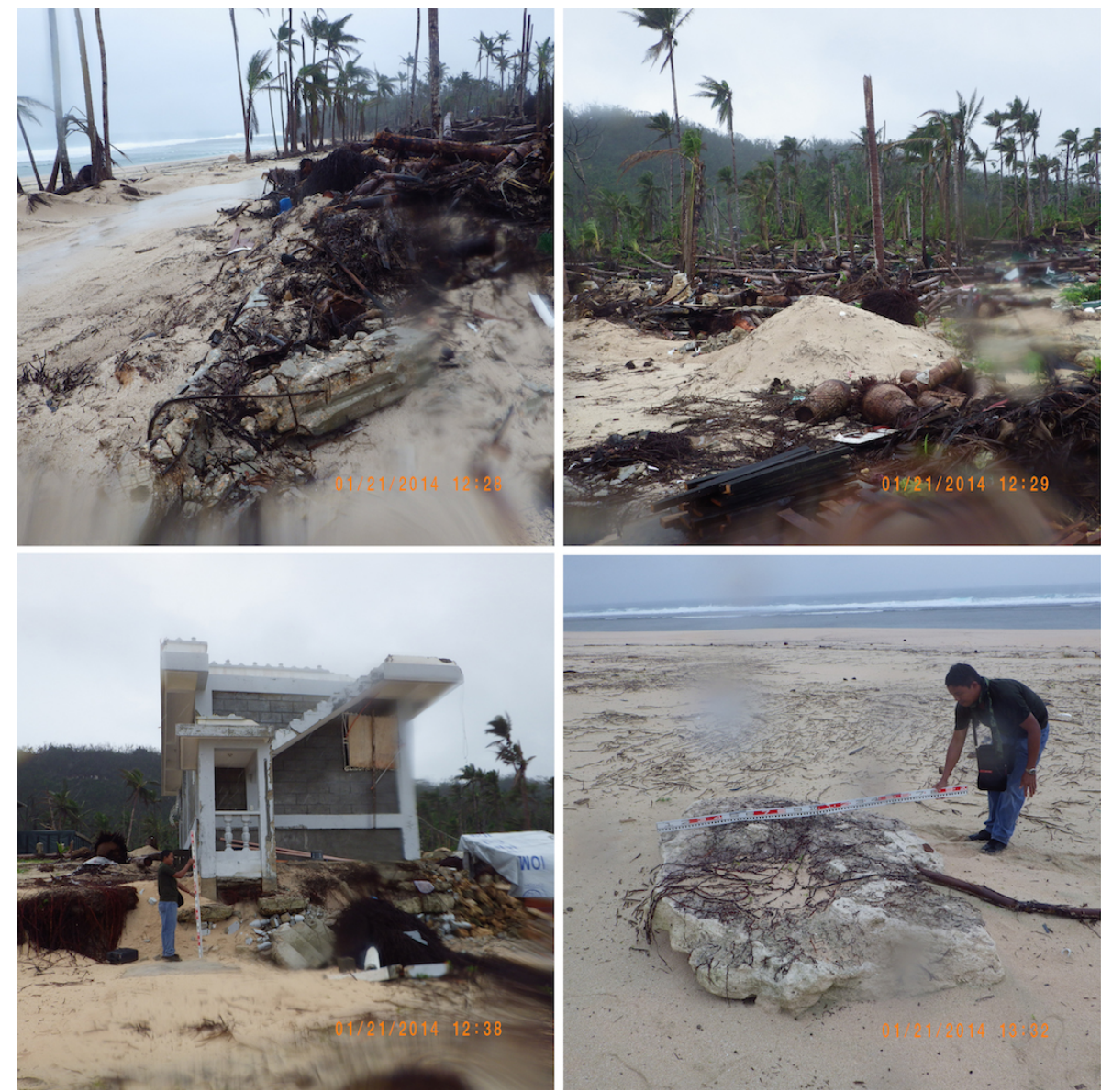

Figure 14. Jagnaya Beach area, east of Salcedo village. Extensive sand erosion and deposition to inland was observed. In addition, coral boulders were observed on the beach, which were possibly carried inland by the waves.

in one low-lying area in Hernani - recorded on video by a member of the NGO Plan Philippines - the wave run-up approached for over $1 \mathrm{~min}$ before receding. Another low-lying area south of Guiuan, located approximately $1 \mathrm{~km}$ from the coast, reported long-duration flooding as waves ran overland to the area. In both cases, a localized dip in topography prevented the water from receding quickly.

\section{Conclusions}

This paper reports on two response activities conducted by IRIDeS after the impact of Super Typhoon Haiyan in the Philippines. First, a rapid damage assessment was conducted through satellite visual images, and then the damage was confirmed qualitatively through field survey observations. The results of the interpretation and the findings of the field survey observations were presented in this paper. The areas interpreted as highly damaged during the satellite image inspection were confirmed as being areas with higher storm surge inundations than those of low-damaged interpreted areas. In addition, the high vulnerability of houses with lightweight roofing materials and the presence of ships carried inland by the storm surge were the cause of devastation in the areas interpreted as highly damaged. A qualitative spatial correlation of inundation heights and damage interpretation can be observe from Fig. 3 and Fig. 7, while the interpreted characteristics of heavy damage in the north district compared to the downtown areas in Tacloban was confirmed during field survey and shown in Fig. 4. Based on our field survey data, Super Typhoon Haiyan affected the Eastern Visayas with storm surge heights from 4 to $8 \mathrm{~m}$ at Leyte Island, with an average inundation height of approximately $6 \mathrm{~m}$. Moreover, surface waves were predominant on the east side of Samar Island, with a maximum height of $11 \mathrm{~m} \mathrm{ob-}$ served at Guiuan. More significant damage was observed in the coastal areas to the north and south of Tacloban city compared to the downtown area. Several ships were taken inland by the surge, causing damage to houses in the Anibong area. Details of the survey point data are appended to this publication. 


\section{The Supplement related to this article is available online at doi:10.5194/nhess-15-805-2015-supplement.}

Acknowledgements. We thank our counterparts in the Philippines for their support before and during the field survey. This field survey was sponsored by the International Research Institute of Disaster Science (IRIDeS) and the Discretional Budget of Tohoku University's president.

Edited by: I. Didenkulova

Reviewed by: H. M. Fritz and two anonymous referees

\section{References}

Barnes, C. F., Fritz, H. M., and Yoo, J.: Hurricane disaster assessment with image-driven data mining in high-resolution satellite imagery, IEEE Transactions on Geoscience and Remote Sensing: Special Issue: Remote Sensing for Major Disaster Prevention, Monit. Assess., 45, 1631-1640, 2007.

Bricker, J., Takagi, H., Mas, E., Kure, S., Adriano, B., Yi, C., and Roeber, V.: Spatial variation of damage due to storm surge and waves during Typhoon Haiyan in the Philippines, J. Jpn. Soc. Civil Eng., Ser. B2 (Coast. Eng.), 70-2, I_231-I_235, 2014.

Daniell, J., Mühr, B., Girard, T., Dittrich, A., Fohringer, J., Lucas, C., and Kunz-Plapp, T.: Super Typhoon Haiyan/Yolanda Report No. 2, Tech. Rep. 2, CEDIM FDA, 2013.

Fritz, H.M., Blount, C., Sokoloski, R., Singleton, J., Fuggle, A., McAdoo, B.G., Moore, A., Grass, C., and Tate, B.: Hurricane Katrina storm surge distribution and field observations on the Mississippi Barrier Islands, Est. Coast. Shelf Sci., 74, 12-20, doi:10.1016/j.ecss.2007.03.015, 2007

Fritz, H. M., Blount, C., Thwin, S., Thu, M., and Chan, N.: Cyclone Nargis storm surge in Myanmar, Geoscience, 2, 448-449, 2009.

Gokon, H. and Koshimura, S.: Mapping of building damage of the 2011 Tohoku earthquake tsunami in Miyagi prefecture, Coast. Eng. J., 54, 1250006-1, doi:10.1142/S0578563412500064, 2012. IRIDeS, International Research Institute of Disaster Science: IRIDeS Fact-finding missions to Philippines, IRIDeS Report, 17 May 2014, available at: http://irides.tohoku.ac.jp/media/files/ IRIDeS_Report_Haiyan_20140527.pdf, 2014.

Jordan II, M. R. and Clayson, C. A.: A new approach to using wind speed for prediction of tropical cyclone generated storm surge, Geophysical Research Letters, 35, L13802, doi:10.1029/2008GL033564, 2008.
Kerry, E.: Divine Wind, The History and Science of Hurricanes, Oxford Univ. Press, 221-226, 2005.

Koshimura, S., Oie, T., Yanagisawa, H., and Imamura, F.: Developing fragility functions for tsunami damage estimation using numerical model and post-tsunami data from Banda Aceh, Indonesia, Coast. Eng. J., 51, 243-273, doi:10.1142/S0578563409002004, 2009.

Mas, E., Koshimura, S., Suppasri, A., Matsuoka, M., Matsuyama, M., Yoshii, T., Jimenez, C., Yamazaki, F., and Imamura, F.: Developing Tsunami fragility curves using remote sensing and survey data of the 2010 Chilean Tsunami in Dichato, Nat. Hazards Earth Syst. Sci., 12, 2689-2697, doi:10.5194/nhess-12-2689-2012, 2012.

Mas, E., Kure, S., Bricker, J., Adriano, B., Yi, C., Suppasri, A., and Koshimura, S.: Field survey and damage inspection after the 2013 Typhoon Haiyan in The Philippines, J. Jpn. Soc. Civil Eng., Ser. B2 (Coast. Eng.), 70-2, I_1451-I_1455, 2014.

Mori, N., Kato, M., Kim, S., Mase, H., Shibutani, Y, Takemi, T., Tsuboki, K., and Yasuda, T.: Local amplification of storm surge by Super Typhoon Haiyan in Leyte Gulf, Geophys. Res. Lett., 41, 5106-5113, doi:10.1002/2014GL060689, 2014.

Morgerman, J., Reynolds, J., and Thomas, M.: iCyclone Chase Report - Final, Tech. rep., iCyclone, available at: http://www.icyclone.com/upload/now/feb2014/iCyclone Chase_Report_HAIYAN2013_FINAL.pdf (last access: 27 March 2015), 2014.

NDRRMC: SitRep No 108 Effects of Typhoon "YOLANDA" (HAIYAN), Tech. rep., National Disaster Risk Reduction and Management Council (NDRRMC), 2014.

Ramírez-Herrera, M. T. and Navarrete-Pacheco, J. A.: Satellite data for a rapid assessment of tsunami inundation areas after the 2011 Tohoku Tsunami, Pure Appl. Geophys., 170, 1067-1080, doi:10.1007/s00024-012-0537-x, 2012.

Suppasri, A., Koshimura, S., and Imamura, F.: Developing tsunami fragility curves based on the satellite remote sensing and the numerical modeling of the 2004 Indian Ocean tsunami in Thailand, Nat. Hazards Earth Syst. Sci., 11, 173-189, doi:10.5194/nhess11-173-2011, 2011.

Tajima, Y., Yasuda, T., Pacheco, B. M., Cruz, E. C., Kawasaki, K., Nobuoka, H., Miyamoto, M, Asano, Y., Arikawa, T., Ortigas, N., Aquino, R., Mata, W., Valdez, J., and Briones, F.: Initial report of JSCE-PICE joint survey on the storm surge disaster caused by Typhoon Haiyan, Coast. Eng. J., 56, 1450006, doi:10.1142/S0578563414500065, 2014.

Wegscheider, S., Schneiderhan, T., Mager, A., Zwenzner, H., Post, J., and Strunz, G.: Rapid mapping in support of emergency response after earthquake events, Nat. Hazards, 68, 181-195, doi:10.1007/s11069-013-0589-y, 2013. 